\title{
Criação de saberes mediados pelo laptop educacional em uma escola UCA
}

\author{
Andrea Pinheiro Paiva Cavalcante ${ }^{1}$, José Aires de Castro Filho ${ }^{1}$, \\ ${ }^{1}$ Programa de Pós-Graduação em Educação Brasileira - Instituto UFC Virtual - \\ niversidade Federal do Ceará (UFC). Campus do Pici - Brazil \\ Andrea, aires\} @virtual.ufc.br
}

\begin{abstract}
RESUMO: O presente trabalho aborda a criação de saberes com laptops educacionais em uma Escola participante do Projeto Um Computador por Aluno (UCA). A discussão teórica, amparada nas proposições dos Multiletramentos e da Educomunicação, relacionando com novas aprendizagens na escola. O estudo acompanhou alunos do $6^{\circ}$ ano em uma atividade de produção de slides usando o laptop educacional. A experiência analisada reforça o entendimento de que práticas de multiletramento possibilitam o desenvolvimento de competencias ensejadas pelo uso do computador. Dentre as muitas atividades realizadas com o computador, a criação de slides é referenciada pelos estudantes como sendo uma das mais significativas. Tal exercício permitiu aos estudantes manifestar como percebem o espaço físico escolar e como se sentem responsáveis pelos cuidados com a escola.
\end{abstract}

ABSTRACT: This paper discusses the creation of knowledge with educational laptops at a school from the Project One Computer per Student (UCA). The theoretical discussion is based on the propositions of multiliteracies and Educomunication, relating to new learning in school. The study followed students from 6th grade in an activity of slides composition using na educational laptop. The analyzed experience reinforces the understanding that multiliteracies practices enable the development of skills allowed by computer use. Among the many activities with the computer, slide composition is referenced by students as one of the most significant. This exercise allowed students to express how they perceive the school as a physical space and feel responsible for the taking care of the school.

\section{Introdução}

O presente artigo discute os resultados de uma pesquisa realizada no âmbito de uma escola integrante do Projeto Um Computador por Aluno, em Fortaleza. Tal pesquisa enfatiza a aprendizagem de competências, por parte das crianças e adolescentes, a partir do uso do computador na sala de aula.

Pesquisas comprovam que cada vez mais as crianças brasileiras estão conectadas à internet. Se em 2011 os dados da TIC Domicílios ${ }^{1}$ indicavam que $75 \%$ da população na faixa etária entre 10 e 15 anos acessaram a rede, em 2013 esse percentual chegou a $85 \%^{2}$. Sobre a frequência de uso em $2013,62 \%$ das crianças entre 10 e 15

\footnotetext{
${ }^{1}$ Disponível em http://cetic.br/tics/usuarios/2011/total-brasil/C1/. Acesso 20.08.14

${ }^{2}$ Disponível em http://cetic.br/tics/usuarios/2013/total-brasil/C1/. Acesso 20.08.14
} 
anos relataram acessar a internet todos os dias. $\mathrm{O}$ acesso diário é mais frequente na região Sudeste, com percentual de $75 \%$. No que se refere ao local de acesso, a casa aparece como principal, com $68 \%$, seguida da casa de parentes e amigos, $38 \%$, escola com 37\% e centros pagos, como as lan houses, 26\%. Entre os anos de 2011 e 2013 o acesso à internet na escola cresceu de $35 \%$ para $37 \%$.

Considerando essa realidade, Levin (2007, p. 11) se perguntava se estamos diante de uma infância virtual, já que a nova cultura do audiovisual, cuja centralidade está na imagem, incentivaria novas formas de brincar, sentir e imaginar. Babin e Kouloumdjian (1989) defendem que a exposição de crianças e jovens às tecnologias digitais possibilita a criação de uma nova cultura “[...]inicialmente é uma mixagem das duas culturas, a interpenetração das duas linguagens”. Não apenas porque estamos diante de novas tecnologias de informação e comunicação, mas de uma nova criança ou, como diz Sibília (2012), de novas subjetividades infantis e juvenis. Babin e Kouloumdjian (1989, p. 150) pensa que nesse cenário a escola é ainda mais necessária "para aprender a ligação que as coisas têm com a ação e a sabedoria do viver".

Caberia então à escola articular essa relação entre essa cultura midiática, favorecendo uma aprendizagem mediada por artefatos tecnológicos e, ao mesmo tempo, possibilitando que as crianças aprendam a usar tais artefatos, de modo, a saber, como operam essas tecnologias e possam ter um posicionamento crítico diante delas. Em que medida a escola está favorecendo essas novas aprendizagens? Que novas competências estão sendo experimentadas com o uso do laptop educacional na sala de aula?

Para responder a essas questões, o texto está organizado em quatro seções. Além da Introdução, apresenta-se o referencial teórico, seguida de seção sobre a escola onde a investigação foi realizada e a descrição da atividade com os laptops educacionais e, por último, os significados dos estudantes sobre a experiência.

\section{Multiletramentos e práticas educomunicativas na escola}

O enfoque teórico dialoga com as proposições dos multiletramentos (ROJO, 2012, COPE e KALANTZIS, 2009, LEMKE, 2010) e da educomunicação (SOARES, 2011, MARTIN-BARBERO, 2003, 2008, BELLONI, 2001, 2012).

A presença, cada vez mais intensificada, da mídia no cotidiano de crianças e adolescentes favorece novas possibilidades de aprendizagem, uma autodidaxia, como define Belloni (2001); ou, como situa Martin-Barbero (2011, p. 125), "Novos modos de perceber e de sentir; uma nova sensibilidade". 
Em linhas com tais proposições, consideramos as contribuições da Educomunicação, conceituada por Soares (2011, p 44) como "um conjunto das ações inerentes ao planejamento, implementação e avaliação de processos, programas e produtos destinados a criar e a fortalecer ecossistemas comunicativos".

Compreendemos que essas novas aprendizagens ou essa autodidaxia estão relacionadas mais aos processos, como acontecem dentro e fora da escola, do que propriamente às tecnologias utilizadas. Optamos por trabalhar com a perspectiva dos multiletramentos, significando a necessidade de incorporar nas práticas curriculares da escola, novos letramentos, seja pelas possibilidades de ascensão das tecnologias de informação e comunicação, seja pela diversidade cultural presente nas salas de aula.

Rojo (2012) considera que a validade da proposta da pedagogia dos multiletramentos está em conhecer e compreender como as novas gerações interagem com os conteúdos multimodais e desse conhecimento empreender outras estratégias de ensinar e de aprender. Propõe ela: "Em vez de proibir o celular em sala de aula, posso usá-lo para a comunicação, a navegação, a pesquisa, a filmagem e a fotografia" (p. 27).

Um dos objetivos da pedagogia dos multiletramentos é "criar as condições de aprendizagem que favoreçam o crescimento de um tipo de pessoa confortável consigo mesma, bem como flexível o suficiente para colaborar e negociar com outras pessoas a fim de construir um interesse comum” (COPE; KALANTZIS, 2009, p. 9).

Para Rojo (2012), o trabalho da escola com a pedagogia dos multiletramentos é criar as condições para que os alunos se transformem em criadores de sentidos, com competência técnica nas ferramentas e práticas e capaz de atuar de forma crítica, testando novos significados ao aprendido, por si mesmo no processo de negociação de sentido.

$\mathrm{Na}$ próxima seção apresentamos a experiência de produção de slides em diálogo com a pedagogia dos multiletramentos e da educomunicação.

\section{Aprendendo novas competências com a produção de slides}

A escola, localizada em um bairro da periferia de Fortaleza, tem cerca de 500 alunos distribuídos do $7^{\circ}$ ano do Ensino Fundamental até o $3^{\circ}$ ano do Ensino Médio, integra o projeto UCA desde 2010. Houve acompanhamento das atividades na escola com os computadores do Projeto UCA de 2010 a 2013. Os dados apresentados nessa discussão foram coletados durante o acompanhamento das atividades com o uso do laptop educacional nas aulas de Geografia e História nas turmas dos $6^{\circ}$ anos, durante o ano de 2013. 
No segundo semestre de 2013, durante as aulas de Geografia nas turmas do $6^{\circ}$ ano de uma Escola Estadual de Ensino Fundamental e Médio em Fortaleza, os estudantes foram orientados sobre como produzir slides usando o laptop educacional. A orientação da professora foi para que cada estudante definisse um tema sobre o qual gostaria de apresentar e que produzisse as próprias fotos usando a câmera do notebook.

A intenção era que a partir do tema definido, eles tirassem fotos para articulá-las com o texto dos slides. Cada um deveria preparar a apresentação contendo cinco slides e cinco fotos. Após a orientação, os estudantes saíram em pequenos grupos para a sessão de fotos na própria escola.

A oportunidade de circular pela escola no horário das aulas, com o devido consentimento da professora, deixou todo mundo empolgado. Muitos nem sabiam ainda sobre o tema que iriam escrever, mas circulavam animados com o laptop nas mãos, fotografando o que viam pela frente. Foram momentos curiosos - eles estavam livres para circular pelos espaços da escola com exclusividade, já que naquele horário os demais colegas estavam em sala de aula e talvez por isso mesmo não soubessem bem como proceder inicialmente. Aquele espaço antes tão disputado, agora era somente deles. Os primeiros momentos foram de surpresa e de apuração dos sentidos para o que seria objeto da atenção mais detida de cada um.

Aos poucos, de certa forma seguindo o rastro daqueles já haviam decidido os seus temas, os estudantes foram experimentando também o poder de decidir sozinhos sobre o que seria a temática do trabalho, já que nem sempre essa liberdade de escolha é oferecida a eles, o que provavelmente explique a relutância inicial de não saber o que fazer.

O retorno à sala de aula foi natural: estavam interessados em aprender a fazer os slides e curiosos para saber como as fotos haviam ficado. A professora foi atendendo aos que chegavam e explicava pacientemente como fazer: abrir o editor de apresentações no laptop educacional, o KPresenter, usar os espaços destinados ao título - ela reforçou a importância de ser criado um título para a apresentação - escrever textos curtos e a inserção das fotos em articulação com o texto.

O grupo trabalhou com dedicação na elaboração dos slides cujas temáticas foram variadas: alguns fizeram abordagens sobre amor e outros contemplaram o desenvolvimento da leitura e da amizade, mas a maioria optou por apresentar nos slides o espaço escolar como a quadra, as plantas, o pátio, a importância da limpeza... 
O exercício permitiu, entre outras coisas, que os estudantes observassem a escola não apenas como frequentadores, mas buscando um olhar diferenciado sobre aquele espaço tão conhecido deles. Através dos slides comentaram sobre questões da escola que elegeram como relevantes, tais como o desconforto com as pichações na quadra, o fato da quadra alagar no período das chuvas, o uso inadequado das lixeiras para a coleta seletiva do lixo, a importância das plantas presentes no espaço escolar e a necessidade de cuidar bem da natureza.

A produção dos slides proporcionou a expressão livre dos alunos e revelou significativas questões relacionadas à dimensão dos multiletramentos e também da educomunicação, posto que fez emergir uma questão-chave: a cultura dos estudantes, especialmente no âmbito das mídias.

Sobre esse aspecto faz-se necessário considerar duas questões em discussão com as proposições de Santaella (2007). A primeira é que entendemos, em linha com a autora, que "É através da linguagem que o ser humano se constitui como sujeito e adquire significância cultural (p.91)". O segundo aspecto diz respeito às formas de socialização constituídas nas relações com as mídias. "Os distintos tipos de mídias e as eras culturais que conformam são inseparáveis das formas de socialização que são capazes de criar, de modo que o advento de cada nova mídia traz consigo um ciclo cultural que lhe é próprio" (p.127).

Em outra perspectiva, mas em sintonia com o proposto por Santaella, buscamos situar essas práticas em relação às áreas de intervenção da educomunicação propostas por Soares (2011).

O fato de propor a elaboração de slides sobre a escola fez com que as crianças se engajassem em um diálogo rico de significações, pois expressaram, entre outras coisas, o que pensavam do espaço físico da escola. Ou seja, a possibilidade de expressar esses sentimentos e entendimentos de como a escola carece de cuidados. Na perspectiva educomunicativa, o que importa é "o tipo de mediação que elas podem favorecer para ampliar os diálogos sociais e educativos" (SOARES, 2011, p.18).

$\mathrm{Na}$ perspectiva dos estudantes a quadra foi o espaço mais comentado visto que foi tema de cinco apresentações, do total das doze produzidas. Na apresentação "A quadra e a pichação", , a primeira imagem é uma foto em plano fechado da pichação, como que justificando o título escolhido para nomear o conjunto de cinco slides. No

\footnotetext{
${ }^{3}$ Os textos das apresentações de slides foram transcritos da forma como foram escritos.
} 
segundo slide vem o texto sem imagem: "A pichação dentro da escola causa um transtorno maior para a nossa educação por que a prefeitura nos traz pouco dinheiro".

Que relação pode existir entre a pichação e a ausência de recursos para a escola? Será que o autor quis dizer que o fato de haver espaços pichados fez com a escola não recebesse os recursos devidos por parte do órgão competente, no caso a Secretaria de Educação do Estado ao invés da Prefeitura, já que é uma escola estadual? E a relação entre a pichação e a educação - será que a pichação revela que a educação oferecida não está sendo adequada por que nem mesmo os estudantes zelaram pelo espaço da escola, como patrimônio de todos e picharam a parede da quadra? E o que dizer da relação pichação e transtorno? Em que medida está relação indica que a pichação é por si um ato nocivo ainda mais se praticada dentro da escola?

Ainda que todas essas perguntas não possam ser respondidas elas oferecem margem para uma série de reflexões que poderiam ter sido feitas por ocasião da apresentação do exercício e poderiam indicar como os estudantes se sentem em relação às pichações na escola, entre outros aspectos.

Os demais slides têm fotos de um detalhe de um grafite na parede da quadra e outra imagem mais aberta com uma pessoa em primeiro plano com a trave e algumas pessoas ao fundo.

A segunda apresentação, "A quadra", começa com o seguinte questionamento: "Porque não tem um teto do lado da quadra e é para colocar e não deixem os alunos pixarem. E a quadra é um lugar esportivo e tem que jogar com a quadra sem água mas quando chove alaga a quadra”.

São muitas questões em um só período: o descontentamento com a pichação, com o fato de a quadra alagar e de permanecer com água impossibilitando o uso do espaço de forma adequada. Também provoca a direção da escola a manter a quadra em boas condições ao solicitar que "não deixem os alunos pixarem" e "porque não tem um teto do lado da quadra e é para colocar". É importante observar a postura de alienação do estudante com relação à responsabilidade do cuidar da escola, por ele atribuída apenas à direção e não a toda a comunidade escolar.

Nessa apresentação as imagens são combinadas com textos colocados sempre na parte superior. Uma delas toma todo o espaço do slide e apresenta a trave de futebol e a tabela de basquete. O slide seguinte mostra a pichação e o texto: "A pixação é uma coisa muito idiota por isso que não pode os alunos pixarem". 
A queixa com o fato de a quadra alagar está no terceiro slide, seguida de uma foto com uma visão inusitada da quadra, o teto: "A quadra é um lugar esportivo para nós jogar mas tem dia que a quadra fica com água e é ruim de jogar”. A apresentação termina com a imagem de um grafite feito na parede da quadra, com o texto: "Na quadra tem uma pintura que é legal mas a quadra sem uma rede é ruim".

O aluno usou a criação de slides para expressar como se sente em relação à manutenção da quadra esportiva, o único espaço para uso recreativo da escola, muito disputado nos intervalos, no início e no final de cada período de aula. Talvez faltem oportunidades para livre expressão como essa que os estimulou a perceber a escola de maneira não usual e a manifestar o que foi observado.

Em outra apresentação sobre a quadra, há uma combinação de textos e imagens que alterna reclamação - a cesta de basquete quebrada em texto e foto - com uma imagem contemplativa de uma árvore frondosa em contraste com as arquibancadas de concreto da quadra, seguida da frase: "Como e lindo a natureza". Essa apresentação, aliás, assinada, é concluída com a foto de uma pintura na parede com os dizeres: só existe uma terra, só existe uma chance. "Preserve a natureza".

Mais duas apresentações são sobre a quadra. Uma delas somente com imagens em plano aberto que tomam todo o espaço do slide e que mostram a trave, a tabela de basquete e crianças no espaço, mas sem qualquer texto.

A outra, intitulada "Futebol", exibe vários ângulos da quadra. No primeiro slide aparece o texto: "O futebol e um jogo que qualquer criança do mundo inteiro queria jogar também e um jogo qui outras crianças não querem jogar”. Nos demais slides os textos funcionam como legenda para as fotos: "Um menino com uma bola de futebol olhando um campo de futebol", em referência a uma pintura na parede da quadra; "Um espaço recreativo", para a imagem em plano aberto da quadra; "Uma quadra de futebol", para a foto da trave.

Os melhores trabalhos foram escolhidos pela turma por votação. Entre os selecionados, uma das apresentações sobre a quadra esportiva, já comentada anteriormente. O primeiro colocado foi sobre "As plantas e o meio ambiente”. A autora fez um texto inicial em que explicita a motivação para a escolha do tema.

Observando algumas partes da escola, eu percebi que algumas plantas não estavam em bom estado (algumas muchas e secas), sendo que isso pode prejudicar o nosso meio ambiente. Em algumas dessa situações, eu também encontrei algumas lixeiras fora de ordem(alguns lixos que deveria estar na lixeira de plastico estavam em outras lixeiras).Param mim todos deveriam ajudar a manter a nossa escola sempre limpa, 
pois estaremos ajudando a nossa vida e de tantas outras pessoas (Apresentação As plantas e o meio ambiente).

As fotos que foram apresentadas nos slides variam entre as imagens de plantas do jardim da escola e de cartazes sobre a questão ambiental que estão distribuídos em vários espaços da instituição, mas sem nenhum texto.

O texto inicial mantém o mesmo tom dos demais sobre a quadra - revela descuidos na estrutura da escola na medida em que expõe o descaso com as plantas, mas avança no sentido de propor uma responsabilidade compartilhada, convidando todos aos cuidados com a limpeza da escola.

Talvez se esse exercício tivesse sido proposto por docentes de Língua Portuguesa, o entendimento sobre o resultado da atividade fosse negativo, considerando os muitos erros presentes nos textos. Mas como explicou a professora, que se disse satisfeita com o resultado, já que o objetivo de ensiná-los a fazer slides foi plenamente alcançado, a educadora destacou que embora esse não tenha sido o foco da avaliação dela, todos os textos foram corrigidos.

Tanto as habilidades de autoria, quanto as habilidades críticas e interpretativas voltadas à multimídia transformam potencialmente não apenas a forma como estudantes e professores comunicam suas ideias, mas também as formas como aprendem e ensinam (LEMKE, 2010, p.09).

O processo de transformação entre ensino e aprendizagem é modificado quando são criadas as condições para essa livre expressão na escola, como propõe Freire (1989) porque entende como indissociável, no processo de alfabetização, a leitura concatenada do mundo e da palavra. Aliás, a leitura do mundo, o entendimento da realidade em que o sujeito está inserido, é condição para apreender a ler a palavra.

(...) se antes os textos geralmente oferecidos como leitura aos alunos escondiam muito mais do que desvelavam a realidade, agora, pelo contrário, a alfabetização como ato de conhecimento, como ato criador e como ato político é um esforço de leitura do mundo e da palavra. Agora já não é possível texto sem contexto (FREIRE, 1989, p.19).

As questões tematizadas pelos estudantes são reveladoras de como percebem o espaço escolar e como se colocam como corresponsáveis nos cuidados com esse ambiente, o que de certa forma contraria a visão do senso comum de que os estudantes "não estão nem aí" para os cuidados com a infraestrutura escolar, como está exposto na seção seguinte. 


\section{Conclusão: o significado da produção de slides para os estudantes}

A criação de slides com o laptop educacional foi mencionada por todos os estudantes entrevistados na turma do $6^{\circ}$ ano A - dez no total - como sendo a atividade mais significativa. Quando perguntados sobre o que aprenderam a fazer com a inserção do computador nas rotinas da sala de aula ao longo do ano, a produção dos slides foi citada por todos como a mais relevante porque, além de terem tido uma chance de falar de pontos do cotidiano escolar que os incomodam, eles nunca haviam tido a experiência de fazer os seus próprios slides, especialmente porque decidiram livremente a temática e fizeram as fotografias.

Muitos comentaram que devido ao uso constante do computador nas aulas de História e Geografia perceberam outras possibilidades de uso para o artefato, antes usado quase que exclusivamente para acesso à internet. "Eu já sabia acessar a internet, mas criar documentos, pastas, salvar, copiar, colar, eu aprendi com o UCA", explica uma das estudantes entrevistadas.

Muitos relatos fazem referência à escolha de cursar o $6^{\circ}$ ano nessa escola à presença do computador na sala de aula, mas mesmo sabendo dos recursos que a escola oferecia isso causou certo estranhamento. "Eu sempre estudei com um caderno e um livro em cima da minha mesa. Aí vem um computador na minha mesa. Aí eu já achei estranho, mas eu fui me acostumando", diz uma das entrevistadas.

Pela experiência e pelos relatos dos estudantes percebe-se que a escola exerce um papel significativo na orientação sobre as novas aprendizagens e competências possibilitadas pelo computador na sala de aula, com a mediação do professor, "desconstruindo certos discursos da naturalização da competência midiática infantil e juvenil e do determinismo tecnológico faz-se necessário para entender a complexidade que envolve as novas formas de aprender e ensinar na cultura digital" (FANTIN, 2012, p.103).

\section{Referências}

BABIN, P.; KOULOUMDJIAN, M. F. Os novos modos de compreender: a geração do audiovisual e do computador. São Paulo: Paulinas, 1989.

BELLONI, M. L. O que é mídia-educação. Campinas: Autores Associados, 2001. COMITÊ GESTOR DA INTERNET NO BRASIL. Pesquisa sobre o uso das tecnologias de informação e comunicação no Brasil: TIC Domicílios e TIC Empresas 2011. Disponível em http://cetic.br/tics/usuarios/2011/total-brasil/C1/. Acesso 20.08.14 COMITÊ GESTOR DA INTERNET NO BRASIL. TIC Kids Online Brasil 2013: pesquisa sobre o uso da Internet por crianças $\mathrm{e}$ adolescentes. Disponível em http://cetic.br/tics/usuarios/2013/total-brasil/C1/. Acesso 20.08.14 
COPE, B.; KALANTZIS, M. 'Multiliteracies': new literacies, new learning. Pedagogies: An International Journal, v. 4, p. 164-195, 2009.

FANTIN, M. Cultura digital e aprendizagem multimídia com o uso do laptop na escola. In: Revista Educação On-Line. Rio de Janeiro, no 11, 2012. (p.89-105).

FREIRE, P. A importância do ato de ler em três artigos que se completam. São Paulo:

Autores Associados, Cortez, 1989.

LEMKE, J. Letramento metamidiático: transformando significados e mídias. Trab. Ling. Aplic., Campinas, 49(2): 455-479, Jul./Dez. 2010. Traduzido por Clara Dornelles

(UNIPAMPA/RS). Disponível no endereço: http://www.scielo.br/scielo.php?pid=S0103-

$18132010000200009 \&$ script=sci arttext Acesso em 07 de março de 2014.

LEVIN, E. Rumo a uma infância virtual?: a imagem corporal sem corpo. Petrópolis: Vozes, 2007.

MARTIN-BARBERO, J. Desafios culturais: da comunicação à educomunicação. In: CITELLI, A. O; COSTA, M. C. C (Org.). Educomunicação: construindo uma nova área de conhecimento. São Paulo: Paulinas, 2011.

MIRANDA, L.T. e FANTIN, M. Crianças e tecnologias móveis: um olhar sobre as possibilidades interacionais na escola.In: XXXVI Congresso Brasileiro de Ciências da Comunicação, 2013, Manaus. Anais...São Paulo: Sociedade Brasileira de Estudos Interdisciplinares em Comunicação, 2013.

ROJO, R; M. E. (orgs) Multiletramentos na escola. São Paulo: Parábola Editoria, 2012.

SANTAELLA, L. Linguagens líquidas na era da mobilidade. São Paulo: Paulus, 2007.

SIBILIA, P. Redes ou paredes: a escola em tempos de dispersão. Rio de Janeiro: Contraponto, 2012.

SOARES, I. de O. Educomunicação: o conceito, o profissional, a aplicação: contribuições para a reforma do ensino médio. São Paulo: Paulinas, 2011. 